УДК 81

ББК 81.2

\section{C.В. Коростова}

КОММУНИКАТИВНО ЗНАЧИМОЕ МОЛЧАНИЕ КАК СПОСОБ ПРЕДСТАВЛЕНИЯ ЭМОЦИОНАЛЬНОГО СОСТОЯНИЯ ПЕРСОНАЖА В РОМАНЕ М.А. ШОЛОХОВА «ТИХИЙ ДОН"

Актуальность изучения молчания в аспекте эмоциональной коммуникации связана с общей тенденцией современных работ по лингвопрагматике, исследующих выбор говорящим языковых средств с целью актуализации речевых стратегий. Анализ коммуникативно значимого молчания в романе М.А. Шолохова «Тихий Дон» позволяет говорить о его тесной связи с культурно-этническими нормами поведения, принятыми в среде донского казачества. Кроме того, молчание, занимающее промежуточное положение между невербальными и вербальными средствами выражения эмоционального состояния, способно передать множество эмоций персонажа, которые сложно или невозможно выразить словами.

Ключевые слова: коммуникация, молчание, эмочиональное состояние персонажа.

DOI 10.18522/1995-0640-2020-1-36-44

Коростова Светлана Владимировна канд. филол. наук, доцент кафедры русского языка Института филологии, журналистики и межкультурной коммуникации Южного Федерального университета Тел.: 8-905-429-87-01

E-mail: svetolen@ yandex.ru

(C) Коростова С.В., 2020.
Одним из компонентов коммуникации является молчание, которое приобретает особую значимость в диалогическом общении. Выделенные известным исследователем феномена молчания C.В. Крестинским многочисленные функции коммуникативно значимого молчания в языковом дискурсе можно рассматривать и с точки зрения целей коммуникации как эмотивные и неэмотивные [Крестинский, 2011]. Первые непосредственно связаны с выражением эмоциональных состояний, причем для них характерна воздействующая функция. Вторые регламентируют культурно-эстетические нормы поведения, принятые в социуме, при этом молчание может быть ритуальным, а также соответствовать требованиям этнических или религиозных традиций конкретного этноса.

Анализ диалогических фрагментов романа М.А. Шолохова «Тихий Дон», репрезентирующих конфликтные коммуникативные ситуации, позволил выделить несколько типичных для данного текста функций молчания, актуализация которых способствует выражению эмотивно-оценочных смыслов. Прежде всего это экспрессивная функция, которая предполагает «способность молчания выражать различные психологические состояния коммуникантов: смущение, обиду, страх, недоумение, удивление, волнение, потрясение, ужас, гнев, ненависть, депрессию, гордость, презрение, раскаяние, любовь, напряженность» [Крестинский, 2011, с. 35]. Вторая функция - оценочная, когда молчание выступает как знак 
одобрения или неодобрения предшествующего речевого или неречевого акта. Кроме того, в тексте романа частотны фрагменты, в которых доминирует стратегическая функция, «молчание осознанное, преднамеренное, используемое с какой-либо целью» [Там же, с. 36]. В тех фрагментах романа, где М.А. Шолохов подробно описывает военные действия и статусные отношения между казаками и офицерами, эмотивное молчание может вводиться в текст как знак «социальной роли коммуниканта в обществе, в его иерархической структуре» [Там же]. Следует признать, что выделенные функции часто пересекаются, проявляясь в одной изображенной в романе коммуникативной ситуации, т.е. молчание полифункционально.

По мнению Т.Р. Копыловой, молчание - это «контекстуально зависимый конструкт». Ссылаясь на работы Д. Курзона, ученый делает вывод о том, что «молчание подобно речи, молчание - это речь минус звук» [Копылова, 2015, с. 118], что означает возможность реализации в процессе молчания речевых стратегий. Речевые стратегии, на основании типа взаимодействия между коммуникантами, можно разделить на две группы: кооперации (стратегии сотрудничества) и конфронтации (конфликтные стратегии), последние определяют эмотивный характер молчания. Очевидно, что применение конфронтационных стратегий вызывает у собеседника негативную установку и ответную отрицательную реакцию, которая может быть выражена и с помощью молчания, отказа от речевого акта.

В живом общении конфликтные стратегии вербализуются в эмотивном диалоге, где говорящие используют различные средства выражения эмотивно-оценочных значений с целью воздействия на собеседника. Однако эмотивные состояния могут быть репрезентированы и тогда, когда один из участников коммуникации молчит.

Эмотивное молчание в значении угрозы и оценочное молчание как реакция на предшествующую диалогическую реплику, семантика которого «считывается» с внешних признаков - жестов, мимики, - это два типичных способа представления эмоций героев, которые используются М.А. Шолоховым в романе «Тихий Дон».

Молчание-угроза в конфликтной ситуации изображено писателем уже в первой главе романа: «Хозяин вышел на крыльцо, кланяясъ:

- За чем добрым пожаловали, господа старики?

Толпа, подступая к крыльцу, немо молчала» [Ч. 1, гл. 1].

Речь идет о жестокой расправе с турчанкой, женой Прокофия Мелехова, которую казаки обвинили в колдовстве. Молчание в этой ситуации означает прямую угрозу, исходящую от толпы, охваченной ненавистью, причем писатель интенсифицирует эту невербализованную стратегию семантическим повтором. Общеизвестно, что немые люди не способны говорить, для них молчание - естественное состояние, тем более угнетающим представлено эмоциональное состояние казаков, а сама ситуация оценивается М.А. Шолоховым как неестественная, противоречащая общечеловеческим ценностям. 
В романе «Тихий Дон» молчание толпы представлено и в тех фрагментах, когда героев охватывают чувства страха, удивления, связанные с военными действиями, с осознанием невозможности убивать живых людей, нарушая нравственный закон, например:

«По улицам, крохотные отсюда, сновали люди, прудили переулки обозы, мельтешились конные. Григорий, шуря глаза, глядел из-под ладони; он различал даже серую, чужую окраску мундиров. Возле города бурели свежевырытые логова окопов, над ними кишели люди.

- Сколько их... - изумленно протянул Прохор.

Остальные молчали, зажатые в кулаке одного чувства. Григорий прислушивался к учащенному бою сердца (будто кто-то маленький, но тяжелый, там, в левой стороне груди, делал бег на месте) и сознавал, ито владеет им совсем иное чувство при взгляде на этих чужих людей, чем то, которое испытывал он на маневрах, видя “противника"» (Ч. 2, гЛ. V).

Молчание как эмотивная реакция на диалогическую реплику и молчание как желание обдумать и выразить мысль представлены в авторском повествовании во фрагменте первой части романа, когда Пантелей Прокофьевич и Григорий едут домой после рыбалки: «Собрались. Григорий оттолкнулся от берега. Проехали половину пути. По лицу отия Григорий видел, что хочет тот что-то сказать, но старик молча поглядывал на разметанные под горой дворы хутора.

- Тьь, Григорий, вот что... - нерешительно начал он, теребя завязки лежавщего под ногами мешка, - примечаю, ты, никак, с Аксиньей Астаховой...

Григорий густо покраснел, отвернулся. Воротник рубахи, врезаясь в мускулистую прижженную солнцегревом шею, выдавил белую полоску.» (Ч. 1, гл. ІІ).

Молчание главного героя сопровождается внешними изменениями: покраснение кожи лица и поворот головы от собеседника свидетельствуют о том, что он испытывает чувство стыда, понимая анормативность своего поведения, нарушающего православный нравственный закон. Стыдливость для русского языкового сознания связана с чувством вины. В словарном толковании глагола «стыдиться» заключена, по мнению авторов Большого толкового словаря синонимов русской речи, семантическая идея: «испытывать/испытать чувство неловкости, вины от сознания предосудительности, неблаговидности своего поступка, поведения, переживание которого связано с ожиданием проявления отрицательного отношения к себе со стороны окружающих. <..> внешне это выражается в том, что человек держится неуверенно, униженно, у него виноватая поза, он часто потеет, краснеет... [Большой толковый словарь синонимов русской речи, 2008, с. 353 - 354].

Замена речи молчанием рассматривается как нулевая вербальная реакция, семантика которой зависит от конкретной ситуации и содержания предыдущей реплики диалога. Речевая стратегия говорящего в представленном фрагменте романа М.А. Шолохова - воздействовать 
на сознание собеседника - реализуется в два этапа: первый - невербальный, когда молчание сопровождается мимическими движениями героя, Пантелея Прокофьевича Мелехова, второй - вербальный, в котором выражено недовольство и сомнения относительно поведения сына, но и нежелание обидеть близкого человека ложными подозрениями. Молчание Григория - это проявление нежелания продолжать разговор, внешняя мимическая реакция на реплику отца, уход от конфронтации. Герой находится в состоянии неопределенности по отношению к Аксинье, он еще не разобрался в своих чувствах, именно поэтому не может ни противостоять реплике отца, ни успокоить его отрицанием подозрений.

«До пристани молчали оба. Уже подъезжая к берегу, отеи, напомнил:

- Гляди, не забудь, а нет - с нонешнего дня прикрыть все игрища. Чтоб с базу ни шагу. Так-то!

Промолчал Григорий. Примькая баркас, спросил:

- Рьбу бабам отдать?

- Понеси купцам продай, - помягчел старик, - на табак разживешься.

Покусывая губы, шел Григорий позади отия. «Выкуси, батя, хоть стреноженный уйду ноне на игрище», - думал, злобно обгрызая глазами крутой отцовский затылок» (Ч. 1, гл. ІІ).

Молчание героев отнюдь не означает, что они пришли к единому мнению. Каждый из них имеет собственный взгляд на события. Однако статусное молчание Григория, для которого, как и для любого казака, отец является главой семьи и его слово незыблемо, свидетельствует о стратегии ухода от конфронтации, хотя внутренняя речь героя и его мимика (покусывая губы) говорят о том, что собственные желания оказываются приоритетными. Кроме того, молчание главного героя - это и способ переменить тему, воздействовать на сознание собеседника, на его эмоциональное состояние.

Для главного героя романа Григория Мелехова более значимой оказывается не спонтанная, а обдуманная речь, особенно в конфликтных ситуациях. Именно молчание как возможность разобраться в своих мыслях, принять правильное решение или, наоборот, уйти от необходимости ответа на поставленный вопрос представлено в ситуации диалога с Аксиньей:

«Аксинья удерживает вздох и снова гладит и разбирает спутанный Гришкин чуб.

- Убъет меня Степан... - не то спрашивает, не то утвердительно говорит она.

Григорий молчит. Ему хочется спать. Он с трудом раздирает липнущие веки, прямо над ним - мерцающая синевою чернь Аксиньиньх глаз.... Аксинья хватает неподатливые, черствые на ласку Гришкинь руки, жмет их к груди, к холодньм, помертвевшим щекам, кричит стонущим голосом: 
- На что тыь, проклятый, привязался ко мне? Что я буду делать?. Гри-и-ишка!. Душу ты мою вынаешь!. Сәубилась я... Придет Степан - какой ответ держать стану?. Кто за меня вступится?

Григорий молчит. Аксинья скорбно глядит на его красивый хрящеватый нос, на покрытые тенью глаза, на немые губы...» (Ч. 1, гл. ХІІ)

Оценочная функция молчания выражена и во фрагменте диалога Пантелея Прокофьевича и Григория о судьбе Натальи:

«Григорий, хлебая щи, изредка вглядывал на Наталью, но лица ее не видел: она сидела к нему боком, низко опустив над вязальными спицами голову. Пантелей Прокофьевич первый не выдержал общего молчания; кашлянул скрипуче и деланно, сказал:

- Наталья вот собирается уходить.

Григорий собирал хлебным катышком крошки, молчал» (Ч. 2, гл. Х).

Большая казачья семья единодушна в осуждении того, кто нарушил нравственный закон. Григорий Мелехов понимает отчужденность близких, но не хочет принимать решение, которое противоречило бы его внутренней убежденности в праве на любовь. Именно поэтому эмоциональное напряжение героя и неопределенность ситуации выражены в молчании, которое сопровождается сосредоточенными движениями: надо занять чем-то руки, сдержаться, чтобы не выдать своих эмоций.

В ситуациях молчания, связанных с главным героем романа, отражается особенность его самосознания, о которой убедительно пишет Е.А. Костин: «Основной особенностью самосознания Григория Мелехова является то, что это “незастывшее”, становящееся самосознание, определяющее себя в постоянном развитии. Это самосознание синкретической природы, когда чувство, мысль, действие не разделились настолько, чтобы стать предметами отдельного анализа внутри самого сознания. Его самосознание направлено на совершение диалога с действительностью как раз в своих собственных пределах» [Костин, 2010, с. 329]. Именно эта «синкретическая природа» самосознания Григория отражается в ситуациях, когда молчание является нулевой реакцией на предшествующие диалогические реплики. Герой вступает во внутренний диалог с окружающим его миром, о котором читатель узнает из авторского повествования:

«...- А править нами кто будет?

- Сами! - оживился Подтелков. - Заберем свою власть - вот и правило. Лишь бы подпруги нам зараз чудок отпустили, а скинуть Калединых сумеемся!

Остановившись у запотевшего окна, Григорий долго глядел на улииу, на детишек, игравших в какую-то замысловатую игру, на мокрые крыши противоположных домов, на бледно-серые ветви нагого осокоря в палисаднике и не слышал, о чем спорили Дроздов с Подтелковым; мучительно старался разобраться в сумятице мыслей, продумать что-то, решить.

Минут десять стоял он, молча вычерчивая на стекле вензеля. За окном, над крышей низенького дома, предзимнее, увядшее, тлело на за- 
кате солнце: словно ребром поставленное на ржавый гребень крыши, оно мокро багровело, казалось, что оно вот-вот сорвется, покатится по ту или эту сторону крыии.» (Ч. 5, гл. II).

Экспрессивная и оценочная функции молчания присущи и внутренней речи персонажей романа М.А. Шолохова «Тихий Дон». По сути внутренняя речь выступает как ситуация молчания, в которой герой размышляет о себе и о мире. Например: «Григорий положил руку на широкую, рабочую спину жены, в первый раз подумал: “Красивая баба, в глаза шибается... Как же она жила без меня? Небось, завидовали на нее казаки, да и она, может, на кого-нибудь позавидовала. А что, ежли жалмеркой принимала?" От әтой неожиданной мысли у него екнуло сердце, стало пакостно на душе. Он испьтующе поглядел в ее розовое, лоснившееся и благоухавшее огуречной помадой лищо.» (Ч. 5, гл. ХІІ). Подозрения Григория по отношению к Наталье рождаются не столько потому, что он сам не раз ходил к жалмеркам (ведущим свободный образ жизни казачкам, мужья которых находились на военной службе), сколько из-за пробудившегося чувства ревности.

По мнению Л.С. Выготского, во внутренней речи «смысл слова никогда не является полным. В конечном счете он упирается в понимание мира и во внутреннее строение личности в целом... Это речь, в которой формируется мысль» [Выготский, 1934, с. 306]. Заметим, что внутренняя речь не только формирует мысль, но и способна изменить эмоциональное состояние человека, повлиять на его дальнейшие действия.

Молчание как внутренняя речь способствует достижению определенной коммуникативной цели - «помощи себе». «Самоутешение как основное намерение персонажа романа может быть достигнуто разными способами: проявлением горя, возмущения, удивления, оправданием своих действий, т.е. в результате эмоциональной реакции на ситуацию» [Коростова, 2013, с. 109]. Например, в последней главе романа Григорий Мелехов эмоционально оценивает ситуацию недавнего прошлого:

«Потом Григорий стал думать о детях. Какие-то они стали не по летам сдержанные, молчаливые, не такие, какими были при матери. Слишком много отняла у них смерть. Они напуганы. Почему Полюшка вчера заплакала, когда увидела его? Дети не плачут при встрече, это на них непохоже. О чем она подумала? И почему в глазах ее мелькнул испуг, когда он взял ее на руки? Может быть, она все время Әумала, что отца нет в живых и он никогда больше не вернется, а потом, увидев его, испугалась? Во всяком случае он, Григорий, ни в чем не виноват перед ними. Надо только сказать Аксинье, чтобы она жалела их и всячески старалась заменить им мать... Пожалуй, они привяжутся к мачехе. Она ласковая, добрая баба. Из любви к нему она будет любить и детей...» (Ч. 8, гЛ. VII).

Эмоциональное состояние героя в начале внутреннеречевого события отличается от финального. «Сдержанность в проявлении эмоций отражается в первых трех конструкциях, представляющих собой повествовательные предложения. Невозможность до конца осмыслить 
и дать определенную оценку ситуации прошлого предопределяет негативные эмоции персонажа, что выражается на лексическом уровне («nлачут», «заплакала», «испуг») и на уровне синтаксиса - в вопросительных риторических конструкциях. Риторические вопросы, типичные для внутренней речи, подтверждают предположение психологов о двойственности, диалогичности человеческого сознания. Человек, размышляя о происходящих событиях, сравнивает свои внутренние мотивации с внешними стимулами и из этого сравнения, как в предшествующем примере, конструирует намерение или программу действий с учетом желаемых последствий» [Коростова, 2013, с. 110].

Эмоциональные состояния персонажей романа и отношения между ними М.А. Шолохов часто комментирует и во внутренней речи, и в описании конфликтной ситуации, предшествующей молчанию. Например, во фрагменте романа, когда Наталья приходит в Ягодное к Аксинье, молчание определяет эмоциональное состояние героинь, их отношение друг к другу:

«Аксинья побледнела, угадав Наталью, медленно двинулась навстречу. Они сошлись на середине двора. На чириках Натальи лежал густой слой дорожной пыли. Она остановилась, безжизненно уронив большие рабочие руки, сапно дыша, пьтталась и не могла выпрямить изуродованную шею; оттого казалось, что смотрит она куда-то в сторону.

- Я к тебе, Аксинья... - сказала она, облизывая обветрившиеся губы сухим языком.

Аксинья быстро оглядела окна дома и молча пошла в людскую, в свою половину. Наталья шла позади. Слух ее болезненно скоблило шорохом Аксиньиного платья.

“От жары, должно быть, в ущах больно”, - выцарапалась из вороха мыслей одна» (Ч. 3, гл. ХІХ).

Молчание Аксиньи ставит ее в эмоционально более высокое положение, коммуникация с первых минут становится психологически статусной. Молчание Аксиньи связано еще и с желанием говорить один на один, именно поэтому ее взгляд упал на окна: убедилась, что никто не наблюдает за встречей с Натальей. Восприятие Натальи в предконфликтной ситуации сродни болезни: ее внутреннее негативное эмоциональное состояние, усиленное душевным страданием, ревностью обостряет слух; мысли, которые рождаются в ее сознании, неопределенны, поскольку чувства подавляют их.

Таким образом, анализ фрагментов романа, в которых М.А. Шолохов использует коммуникативно значимое молчание в качестве способа представления эмоциональных состояний персонажей, позволяет сделать вывод о доминировании экспрессивной и оценочной функций молчания в тексте романа «Тихий Дон». Прагматика эмотивного молчания тесно связана с характеристикой ситуации общения: в конфликтных и предконфликтных ситуациях молчание выполняет функцию эмоционального воздействия, особенно значимую тогда, когда оно заменяет диалогическую реплику. Молчание может быть представлено и как 
внутренняя речь, в этом случае репрезентированный аутодиалог предполагает принятие героем определенного решения, а также позволяет писателю представить причины изменения эмоционального состояния персонажа романа.

\section{Литература}

Большой толковый словарь синонимов русской речи. Идеографическое описание. 2000 синонимических рядов / под ред. Л.Г. Бабенко. М.: АСТ-ПРЕСС КНИГА, 2008. 784 с (Фундаментальные словари).

Выготский Л.С. Мышление и речь. М.; Л.: Огиз; Соцэкгиз, 1934. 325 с.

Копьлова T.P. Молчание: вербальная vs невербальная коммуникация // Вестн. Удмуртского ун-та. История и филология. 2015. Т. 25, вып. 3. С. 116 119.

Коростова С.В. К вопросу об эмотивности художественного текста // Язык. Текст. Дискурс: научный альманах Ставропольского отделения РАЛК / под ред. проф. Г.Н. Манаенко. Вып. 11. Ставрополь: Изд-во СКФУ, 2013. 400 c.

Kostin,Jevgenij. Философия и эстетика русской литературы / Евгений Костин. Vilnius: Vaga, 2010. 432 p.

Крестинский C.B. Молчание как средство коммуникации и его функции в языковом дискурсе // Вестн. ТвГУ. Филология. 2011. Вып. 1. С. 34 - 37.

\section{References}

Bol'shoy tolkovyy slovar' sinonimov russkoy rechi. Ideograficheskoye opisaniye. 2000 sinonimicheskikh ryadov. Pod red. L.G. Babenko. M.: AST-PRESS KNIGA. 2008. 784 p. (Fundamental'nye slovari). (In Russian).

Vygotskiy L.S. Myshleniye i rech'. M.; L., Ogiz; Sotsehkgiz, 1934. 325 p. (In Russian).

Kopylova T.R. Molchaniye: verbal'naya vs neverbal'naya kommunikatsiya. Vestn. Udmurtskogo un-ta. Istoriya i filologiya, 2015, vol. 25, no. 3, pp. 116-119. (In Russian).

Korostova S.V. K voprosu ob ehmotivnosti hudozhestvennogo teksta. Yazyk. Tekst. Diskurs: Nauchnyy al'manakh Stavropol'skogo otdeleniya RALK. Pod red. prof. G.N. Manayenko, vyp. 11. Stavropol': Izd-vo SKFU, 2013. 400 p. (In Russian).

Kostin, Jevgenij. Filosofiya i ehstetika russkoy literatury. [Evgeniy Kostin]. Vilnius: Vaga, 2010. 432 p. (In Russian).

Krestinskiy S.V. Molchaniye kak sredstvo kommunikatsii i yego funktsii v yazykovom diskurse. Vestn. To GU. Filologiya, 2011, no. 1, pp. 34-37. (In Russian).

Svetlana V. Korostova (Rostov-on-Don, Russia)

Communicatively Meaningful Silence as a Way to Express the Emotional States of Characters in the Novel of Mikhail Sholokhov «And Quiet Flows the Don»

Silence is a communicative phenomenon with its own psychological meaning and evaluative semantics. The article treats silence, when it replaces speech, as a zero verbal reaction, the meaning of which depends on the specific communicative situation and on the previous phrase of the dialogue. The research of communicatively meaningful silence in the novel of Mikhail Sholokhov «And Quiet Flows the Don» suggests that it is closely connected 
with the cultural and ethnic norms of behavior that are common among Don Cossacks.

Emotive silence that means a threat and evaluative silence as a reaction to the previous phrase of a dialogue are two of the typical ways to express the emotions of characters that Mikhail Sholokhov uses in his novel «And Quiet Flows the Don». The analysis of such dialogical fragments of the novel that represent communicative situations of conflict made it possible to single out several functions of silence that are typical of this text, and the actualization of these functions helps to express emotive-evaluative meanings. Primarily the expressive and the evaluative functions of silence help the text of the novel to depict a living communicative situation.

Key words: communication, silence, emotional state of a character.

Svetlana V. Korostova - Ph. D. in Philology, associate professor of the Department of Russian language, Institute of Philology, Journalism and Cross-Cultural Communication of the Southern Federal University. Phone: 8-905-429-87-01, e-mail: svetolen@yandex.ru 